\title{
Influence of High Current-Density Impulses on the Stress-Strain Response and Microstructural Evolution of the Single Crystal Superalloy CMSX-4
}

\author{
Eugen Demler ${ }^{a} *\left(\bullet\right.$, Gregory Gerstein ${ }^{a}$, Andrej Dalinger ${ }^{a}$, Alexander Epishin ${ }^{b}$, Torsten Heidenblut ${ }^{a}$, \\ Florian Nürnberger ${ }^{\circledR}$, Hans Jürgen Maier ${ }^{a}$ \\ Institut für Werkstoffkunde, Leibniz Universität Hannover, Garbsen 30823, Germany \\ ${ }^{b}$ Technische Universität Berlin, Metallische Werkstoffe, Berlin 10623, Germany
}

Received: June 19, 2018; Revised: September 06, 2018; Accepted: September 17, 2018

\begin{abstract}
Owing to the low formability of single-crystal nickel-based materials, single-crystal components are typically cast. Subsequently, a multi-stage heat treatment is carried out in order to partially compensate the dendrite segregation and to stabilize the precipitated $\gamma^{\prime}$-phase. Such components possess a high resistance to creep at elevated temperatures. Since it is known that electrical impulses can be used to increase the formability of various materials, the potential of an electrical high current-density impulse treatment was evaluated for forming of the high strength nickel-based superalloy CMSX-4. Heat treated and pre-deformed specimens were loaded in compression and subjected to short pulses with a high-current density of $2.3 \mathrm{kA} / \mathrm{mm}^{2}$. Depending on the microstructural state, the material demonstrated work hardening or softening as a consequence of the impulse treatment. In addition, experiments were carried out on crept specimens to test whether the current-impulse treatment can be used to reverse creep-related segregation of alloying elements (raft formation). It was possible to observe a change in the concentration of the elements in the $\gamma / \gamma^{\prime}$-phase transition following the currentimpulse treatment. In particular, a local increase in the $\gamma$-forming elements $\mathrm{Cr}, \mathrm{Co}$ and a decrease in the $\gamma$ '-forming elements Ta, Ti was observed after the impulse treatment.
\end{abstract}

Keywords: nickel-based alloy, short current-impulse, plasticity, work hardening and softening, element distribution.

\section{Introduction}

High electrical current densities can influence the mechanical properties of metallic materials by reducing the yield strength. This is referred to by some authors as the "electroplastic effect" "-9. Particularly for materials that are difficult to form, some forming operations can be facilitated using this effect. For example, in the work of Okazaki et al., investigations were carried out on titanium wires ${ }^{2}$, which were subjected to high current densities of over $1000 \mathrm{~A} / \mathrm{mm}^{2}$ and short current-impulses of $0.1 \mathrm{~ms}$. The authors reported reduced yield strengths with increasing current densities. Prior studies show that elevated plasticity is expected for current densities above $100 \mathrm{~A} / \mathrm{mm}^{2}{ }^{10}$. In other words, the electroplastic effect is only clearly observed at high current densities which, owing to the material's electrical resistance, also lead to substantial thermal loading (Joule heating). In order to separate the electroplastic effect from the enhanced plasticity resulting from specimen heating, a few authors employed high temperature materials such as single-crystal nickel-based superalloys. In these materials increased thermally-induced plasticity is only observed between $760^{\circ} \mathrm{C}$ and $1250^{\circ} \mathrm{C}{ }^{11}$. Following the same rationale, investigations were carried out on fcc specimens of a single crystal nickel-cobalt alloy in the study of Gerstein et al. ${ }^{12}$.
The specimens were subjected to short impulses of high current density during compressive loading. This led to a visible forming-relief on the specimen's polished surface, which indicated that additional deformation mechanisms were activated by dislocation slip on the $\{111\}$ plane. Similarly, a drop in yield strength was observed upon application of high current density pulses during compression of single crystal nickel-based alloy PWA $1480^{13}$. In this case, the microstructural analyses indicated a redistribution of dislocations.

Since the different mechanisms of the electroimpulserelated hardening and softening observed in the previous investigations are not yet understood in the nickel-based superalloy $^{12,13}$, the objective of the present study was to shed light on the relationship between application of the high current density pulses and dislocation motion in different microstructural states. These tests were conducted at constant mechanical stresses, which were well below the material-specific compression limit. Given the envisaged application, i.e. use of the electroplastic effect in forging, rolling or deep drawing, the current study also included tests carried out at constant compression rates. Moreover, experiment were conducted to tests whether elemental redistribution by electromigration can be exploited to rejuvenate a microstructure degraded by the formation of rafts. 


\section{Materials and Procedures}

\subsection{Alloy composition and material states}

The chemical composition, determined using energy dispersive spectroscopy (EDS) measurements, is given in Table 1 and in accordance with the manufacturer tolerances.

Samples of CMSX-4 were investigated in four different initial states (cast, heat treated, slightly and severely deformed by creep). In the nearly dislocation-free cast state (see Fig. 1 a), the fine cuboidal $\gamma$ '-precipitates are inhomogeneously present in the $\gamma$ matrix. Following the typical multi-stage heat treatment (Table 2), the $\gamma$ '- precipitates are stabilised and more homogeneously distributed (Fig. 1 b).

For specimens possessing low creep deformation, dislocations are increasingly observed at the $\gamma / \gamma^{\prime}$-phase boundaries (interfacial dislocations according to ${ }^{14}$; $\mathrm{cf}$. Fig. $1 \mathrm{c}$ ). The $\gamma$-phase already begins to preferentially form parallel to the direction of the external compression stress $\sigma$.

In the more severely creep deformed state (see Fig. $1 \mathrm{~d}$ ), a pronounced raft structure is visible that extends parallel to the compression direction. In this state, a high density of interfacial and super dislocations is apparent (according to e.g. ${ }^{21}$ ) from

Table 1. Chemical composition of the CMSX-4 specimens in wt.-\% as determined using EDS (Quantax, Bruker Corp.)

\begin{tabular}{cccccccccc}
\hline $\mathrm{Al}$ & $\mathrm{Ti}$ & $\mathrm{Cr}$ & $\mathrm{Co}$ & $\mathrm{Mo}$ & $\mathrm{Hf}$ & $\mathrm{Ta}$ & $\mathrm{W}$ & $\mathrm{Re}$ & $\mathrm{Ni}$ \\
\hline 5.62 & 1.04 & 6.80 & 10.39 & 0.60 & 0.45 & 6.80 & 4.07 & 2.02 & bal. \\
\hline
\end{tabular}
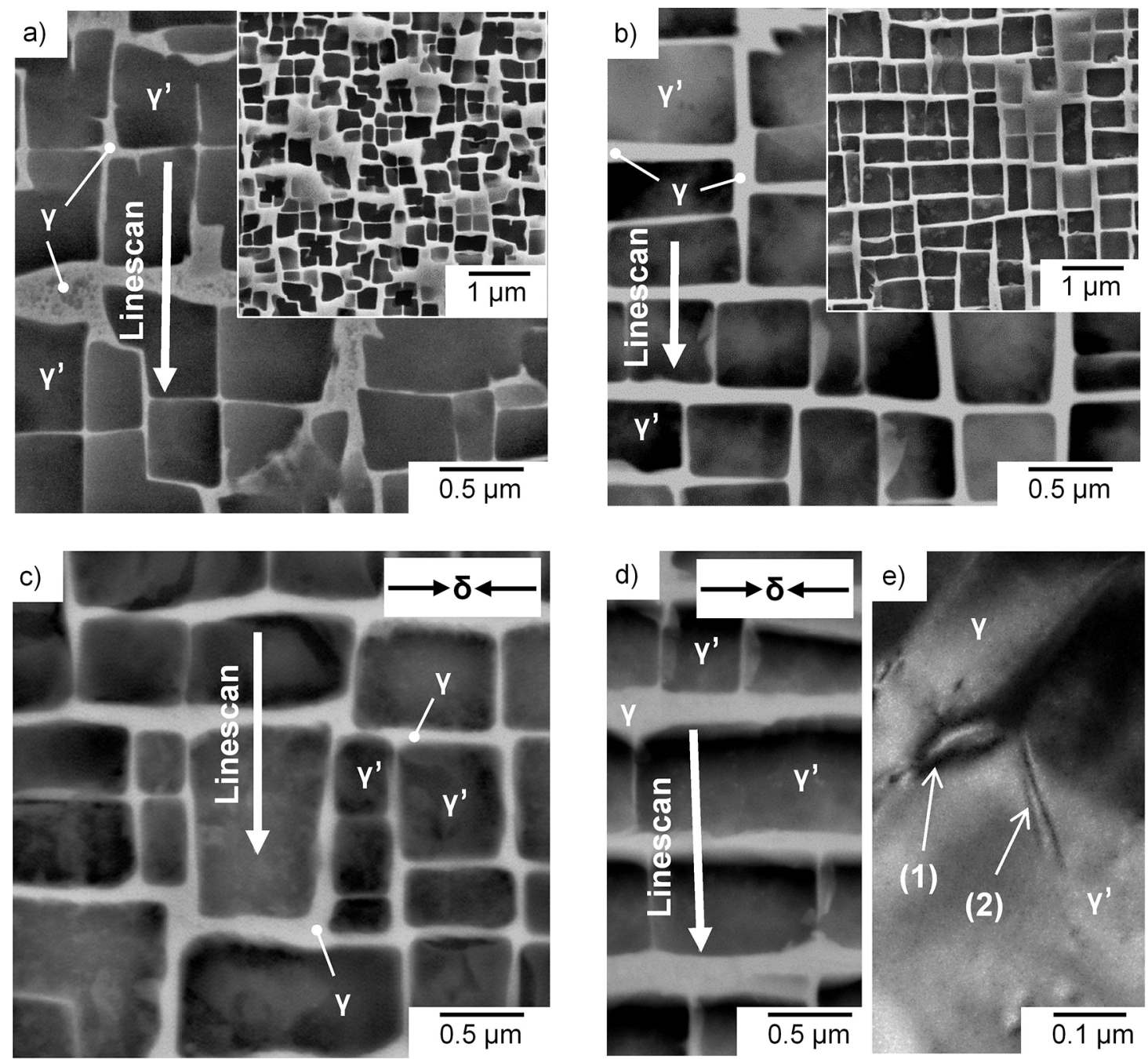

Figure 1. Back scattered electron images recorded perpendicular to the [001]-(loading-)direction of the etched CMSX-4 specimens: a) as-cast condition; b) multi-stage heat treated state; c) at $0.01 \%$ creep strain $\left.\left(950^{\circ} \mathrm{C}, 150 \mathrm{MPa}, 2 \mathrm{~h}\right), \mathrm{d}\right)$ at $0.5 \%$ creep strain $\left(1050^{\circ} \mathrm{C}\right.$, $150 \mathrm{MPa}, 3 \mathrm{~h}$ ); measuring positions of EDS-linescans depicted and e) TEM image of severely creep deformed state with (1) interfacial dislocation and (2) super dislocation; plan of foil [011]; type of the total Burgers vectors of (2) was determined as $b=a<011>$ 
Table 2. Heat treatment employed for CMSX-4 to stabilize the microstructure.

\begin{tabular}{ccc}
\hline & Homogenization & Ageing \\
\hline \multirow{2}{*}{ CMSX-4 } & $1280^{\circ} \mathrm{C} / 1 \mathrm{~h} ; 1290^{\circ} \mathrm{C} /$ & $1140^{\circ} \mathrm{C} / 6 \mathrm{~h} ; 870^{\circ} \mathrm{C}$ \\
& $2 \mathrm{~h} ; 1305^{\circ} \mathrm{C} / 6 \mathrm{~h}$ & $/ 16 \mathrm{~h}$ \\
\hline
\end{tabular}

corresponding transmission electron microscope (TEM) image (see Fig. 1 e).

\subsection{Impulse treatment}

The high-current impulse tests were carried out using a creep rig with a constant applied compressive load (Fig. 2, left) as well as in an universal testing machine from the company Zwick with a given constant compression rate (Fig. 2, right).

For the tests, three $2 \mathrm{~mm} \times 2 \mathrm{~mm} \times 2 \mathrm{~mm}$ cubical specimens per microstructural state and test conditions were used. The specimens were placed between an upper and a lower electrode, which were connected to a high-current impulse generator featuring high capacitance-condensers and short switching times. The duration of the current-impulse that could be periodically introduced into the specimen was varied from 0.1 to $1 \mathrm{~ms}$ at a current strength between 3 and $10 \mathrm{kA}^{13}$. Ceramic insulation plates were employed and a high-speed infrared camera (FLIR ThermaCam SC 3000) was used to monitor the specimen temperature at a maximum frequency of $750 \mathrm{~Hz}$ with a thermal sensitivity of $0.02^{\circ} \mathrm{C}$ at $30^{\circ} \mathrm{C}$. Thus, the surface temperature of the graphite coated specimen (coefficient of emission 0.9) could be accurately monitored with high temporal resolution.

For the tests conducted at a constant nominal strain rate of $0.1 \mathrm{~mm} / \mathrm{s}$, the current-impulses were simultaneously applied whilst the specimens were elastically loaded in compression.
Using the same central compression set-up, continuous pulse tests at constant load were carried out in the creep rig with dead weights (Fig. 2). These tests were stopped after 1000 current-impulses. The detailed test program is summarized in table in Fig. 3.

In the test series V1, compression tests without current-impulses were conducted in order to determine the $0.2 \%$-compression limit of the four material states. In the test series V2, additional periodic current-impulses having a duration of $0.5 \mathrm{~ms}$ and a currentless interval of $3 \mathrm{~s}$ during the compression test were introduced into the specimen oriented in the [001]-direction (see schematic representation in Fig. 3). The maximum applied current density was $2.3 \mathrm{kA} / \mathrm{mm}^{2}$.

In test series V3, the current-impulse treatment was applied perpendicular to the [001]-oriented specimen at a constant applied compressive load of $150 \mathrm{MPa}$ (see Fig. 3). In the test series $\mathrm{V} 4$, the $\mathrm{V} 3$ specimens $0.2 \%$-compression limits were subsequently determined.

\subsection{Electron microscopy}

The elemental composition $c$ at the $\gamma / \gamma^{\prime}$-phase boundaries was analyzed by EDS (voltage $15 \mathrm{kV}$, lateral resolution $\approx 0.6$ $\mu \mathrm{m})$. For the analysis, one specimen each per microstructural state was chosen from the test series $\mathrm{V} 3$, and metallographically prepared perpendicular to the compression direction. After manually grinding with a 2500 grit emery paper, the specimens were polished using VibroMet 2 polisher (Bühler) with the polishing paste Masterprep for about $3 \mathrm{~h}$. After subsequent cleaning in an ultrasonic bath, the specimens' surfaces were etched using an etchant according to Adler ${ }^{15}$.

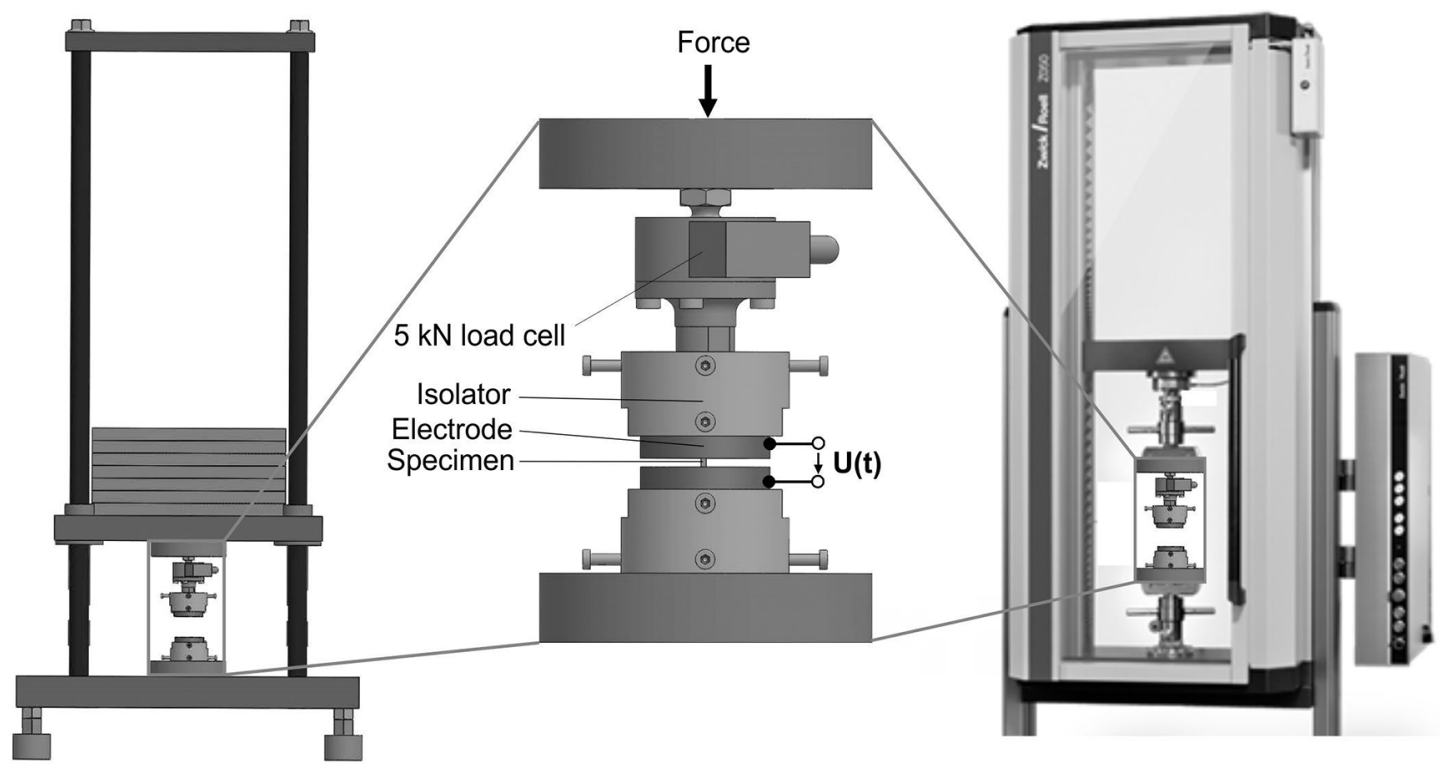

Figure 2. Compression test set-up used to apply high current density impulses at (left) constant load or (right) constant strain rate. 


\begin{tabular}{|c|c|c|c|c|}
\hline $\begin{array}{c}\text { Test } \\
\text { series }\end{array}$ & $\begin{array}{c}\text { No. of } \\
\text { tests }\end{array}$ & Type of test & \multicolumn{2}{|c|}{ Test parameters } \\
\hline V1 & 12 & $\begin{array}{c}\text { Compression test without superimposed } \\
\text { current impulses }\end{array}$ & $\begin{array}{c}\text { Current } \\
\text { impulse } \\
\text { duration }\end{array}$ & $\begin{array}{c}\text { Consity } \\
\text { denty }\end{array}$ \\
\hline V2 & 12 & Compression test with current impulses & $\begin{array}{c}0.5 \mathrm{~ms} \\
\text { (interval 3 s) }\end{array}$ & $2.3 \mathrm{kA} / \mathrm{mm}^{2}$ \\
\hline V3 & 12 & Continuous impulse tests at constant & $\begin{array}{c}0.5 \mathrm{~ms} \\
\text { compression load }\end{array}$ & $2.3 \mathrm{kA} / \mathrm{mm}^{2}$ \\
\hline V4 & 12 & $\begin{array}{c}\text { Compression tests on V3 specimens } \\
\text { without current impulses }\end{array}$ & - \\
\hline
\end{tabular}

V1

$0.2 \%$-compression limit of material states

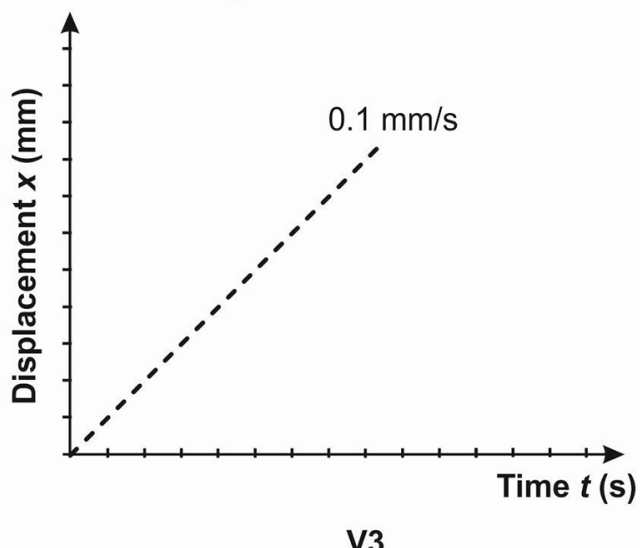

constant compressive load + current impulses

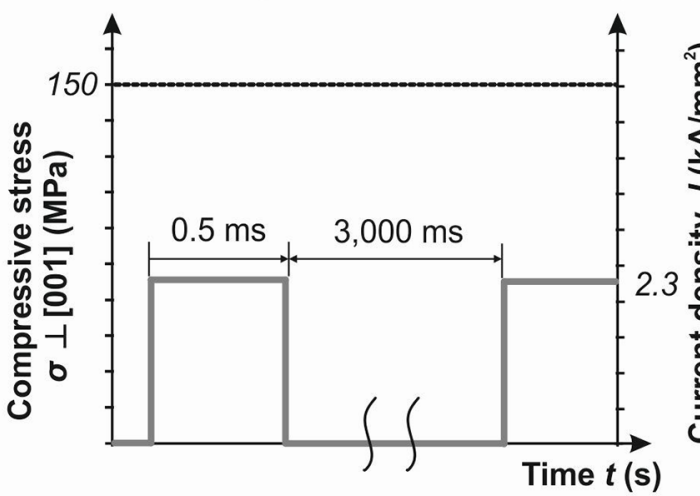

V2

compression tests + current impulses

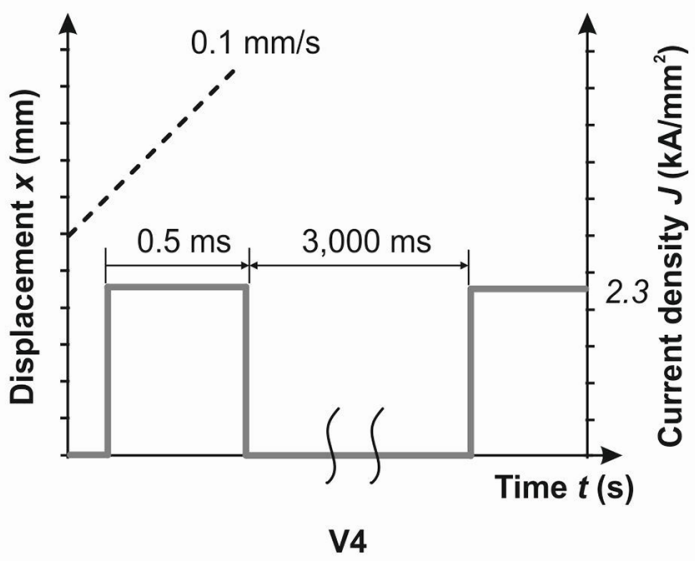

$0.2 \%$-compression limit of V3

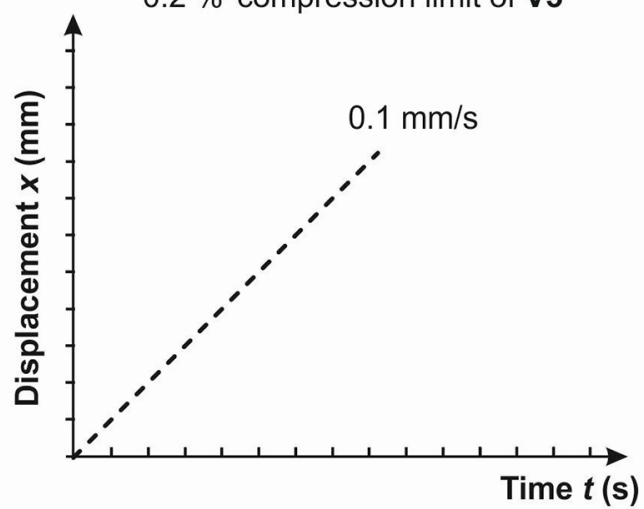

Figure 3. Table with test versions of the high-current impulse tests and schematic representation of the mechanical and electrical loading from test series V1, V2, V3 and V4.

Back-scattered electron (BSD) images of the measuring locations are depicted at which the elemental distribution was measured prior to and after the current-impulse treatment (cf. Fig. 1). For the line scans, one measuring location was chosen in the interdendritic region for each condition since the content of more rapidly diffusing elements is elevated in this region.

\section{Results}

\subsection{Mechanical properties}

Representative stress-strain curves for the four material conditions with and without superposed current-impulses are depicted in Fig. 4. A distinct difference in the material's response can be seen following the application of the electrical 
current impulses (black line). For all four conditions, an abrupt rise in stress of about 70 to $90 \mathrm{MPa}$ is seen after every impulse, which is accompanied by a subsequent drop in stress. Already after the first five current-impulses, the stress level for all microstructural conditions drops significantly below the respective stress without the current-impulses (grey line). It should be noted that this behavior is already clearly observed prior to reaching the plastic region. Only in those specimens which were creep deformed up to $0.5 \%$, does the flow curve of the current-pulse treated material tend to increase to values above the one of the non-treated reference (Fig. 4 d).

The mean values of the compression limits can be found in Fig. 5 for the four materials in their initial condition and after the current-impulse treatment. Prior to the current-impulse treatment, the cast state exhibited the largest compression limit of approx. $830 \mathrm{MPa}$. By contrast, the creep deformed state $(\varepsilon=0.5 \%)$ has the lowest value (approx. $680 \mathrm{MPa}$ ). In the heat treated and the slightly creep deformed $(\varepsilon=0.01 \%)$ condition the material features an approximately identical compression limit of $786 \mathrm{MPa}$ and $783 \mathrm{MPa}$, respectively. Following the current-impulse treatment (current flow perpendicular to the specimen's[001]-orientation), it was possible to measure an increase in the compression limit in the cast (approx. $1.1 \%$ ), heat treated (approx. $8.7 \%$ ) and slightly creep deformed (approx. $3.6 \%$ ) specimens. However, a decrease of about $17 \%$ in the compression limit was obtained for the severely creep deformed state.

\subsection{Elemental distribution at the $\gamma^{\prime} / \gamma / \gamma^{\prime}$-phase boundary}

Table 3 shows the determined $k$-values $\left(k=c_{\text {prior to impulse }}\right.$ treatment $\left./ c_{\text {affer impulse treatment }}\right)$ for the four investigated material conditions. Owing to the small fraction of the elements Mo, Hf and Re and their small change in the local chemical composition, their $k$-values are not included. For the other elements, however, a noticeable redistribution of the elements following the current-impulse treatment was observed. In the as-cast condition, only the $\mathrm{Cr}$ and $\mathrm{W}$ contents increased $(k<1)$ significantly after the current-impulse treatment. In a)

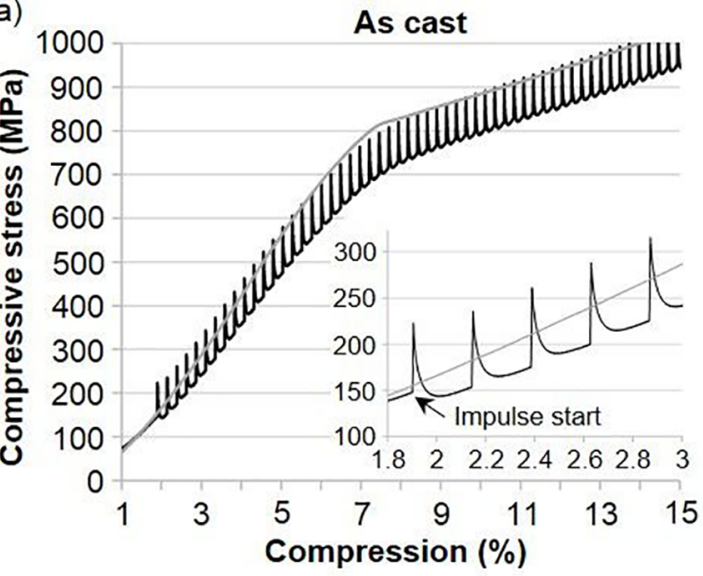

c)

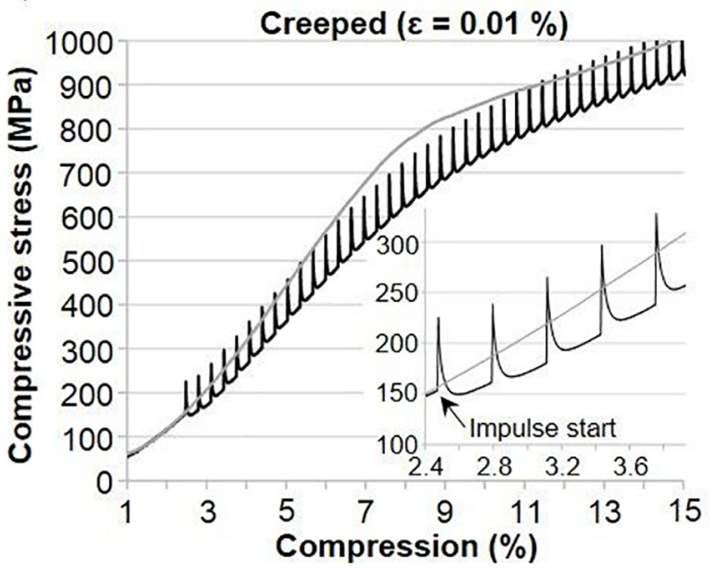

Without impulses b)

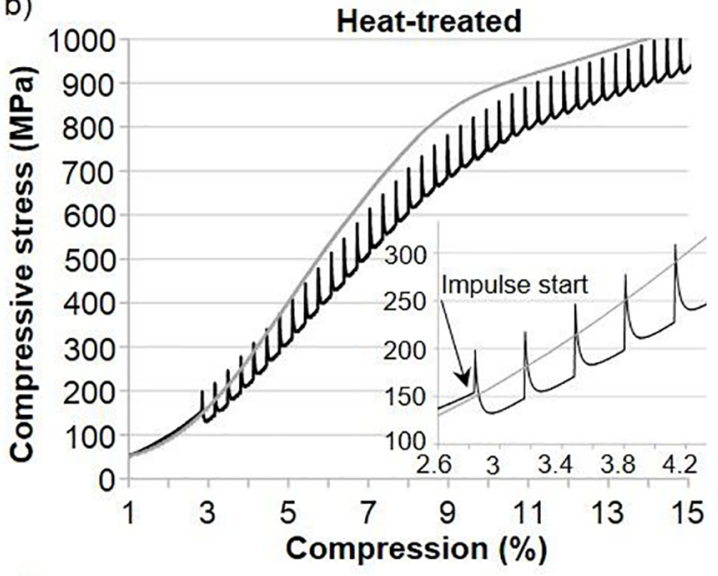

d)

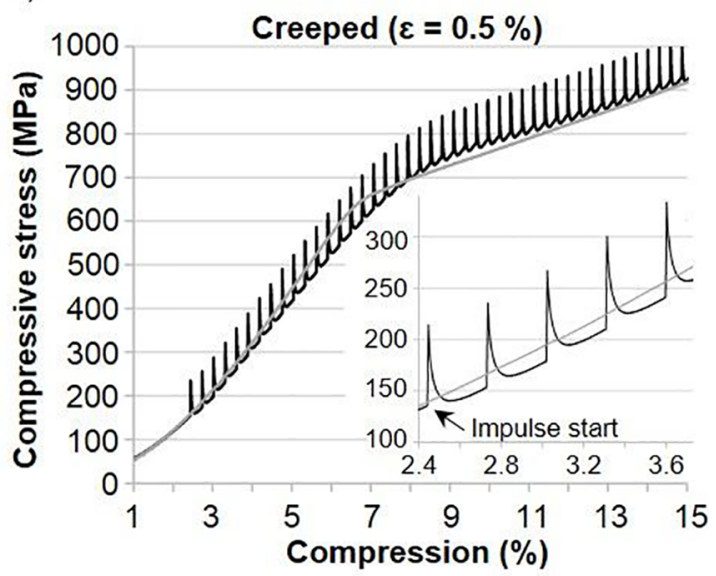

With impulses

Figure 4. Stress-strain curves determined from the compression test on CMSX-4 specimens with and without superimposed electrical current-impulses (test parameters according to Table 3, test series V1 and V2) for the four material conditions a) cast, b) heat treated c) creep strain of $0.01 \%$ and d) creep strain of $0.5 \%$. 
a)

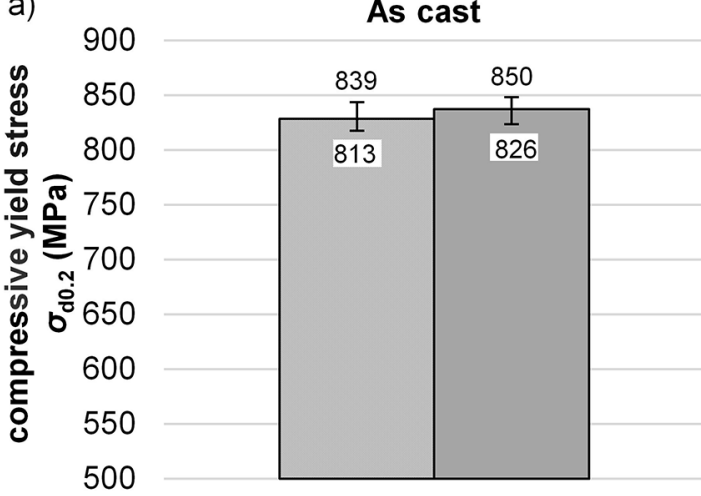

c)

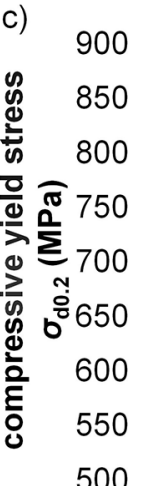

500 b)

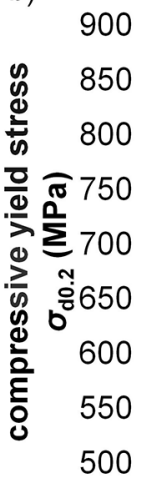

d)

d) 900
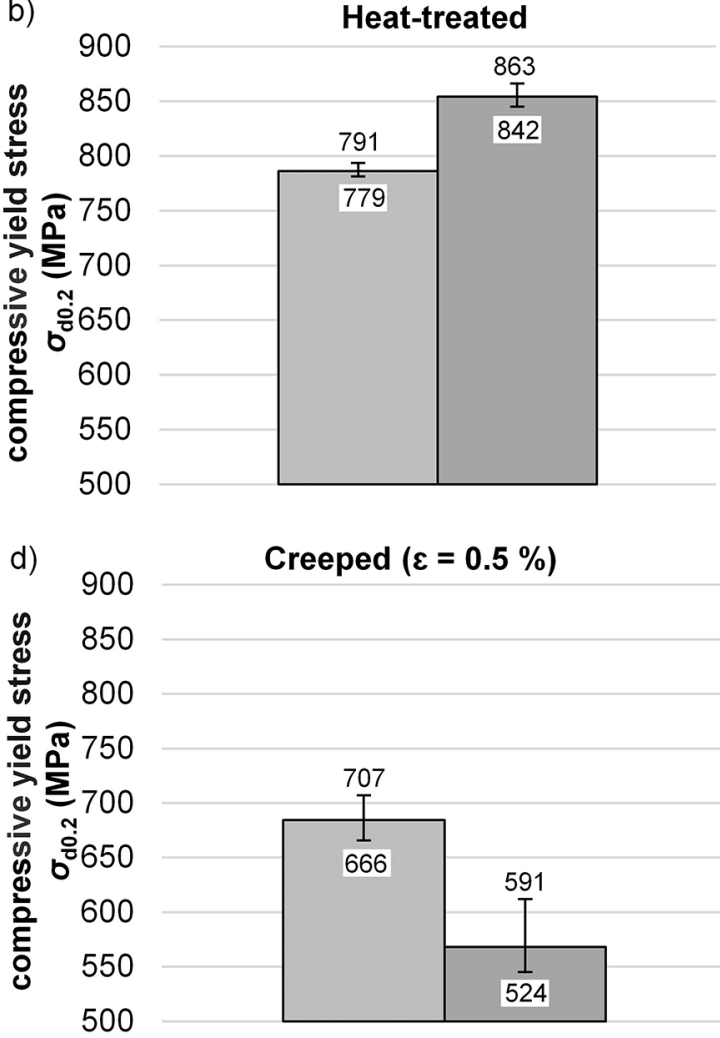

Creeped $(\varepsilon=0.5 \%)$

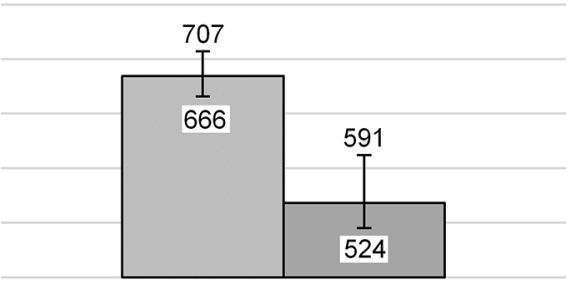

Initial state

Figure 5. Averaged compression limits determined from the CMSX-4 specimens in their initial condition and with prior current-impulse treatment (test parameters according to Table 3, test series V3 and V4) for a) cast, b) heat treated c) creep strain of $0.01 \%$ and d) creep strain of $0.5 \%$ material.

the heat treated state, the content of the $\gamma$-forming element $\mathrm{Cr}$ decreased. However, the contents of $\gamma$-forming elements $\mathrm{Cr}$, Co increased in the creep deformed specimens whilst those of the $\gamma$ '-forming elements Ta, Ti decreased.

\section{Discussion}

\subsection{Influence of the impulse treatment on microstructure and stress-strain response}

The stress-strain curves from Fig. 4 a, b and c reveal that the influence of the electrical current impulses caused a softening during the compression test. In contrast, a nonmonotonic hardening was observed for the severely creep deformed specimens (Fig. 4 d). This can be attributed to the high density of interfacial and super dislocations existing in this condition. Apparently, the current induced dislocation motion assists annihilation of the dislocations that are newly generated during deformation. Since the microstructure in the other conditions features a low dislocation density, the contribution of possible annihilation processes is very low with respect to the degree of deformation.
The abrupt increase in stress of up to $90 \mathrm{MPa}$ with a duration of only a few ms results from the specimens' thermal expansion since these were heated up to $550^{\circ} \mathrm{C}$ during each current-pulse. However, this temperature does not reach the critical temperature range of a decreasing yield stress $\left(>760^{\circ} \mathrm{C}\right)$ for single crystal nickel-based alloys. This material behavior was also previously observed and discussed by Demler et al. for the single crystal nickel-based alloy PWA $1480(\varepsilon=0.1 \%)^{13}$ and on heat-treated CMSX-4 superalloy with pulse duration of 0.3 and $0.5 \mathrm{~ms}^{22}$.

The continuous impulse tests of a constant applied compressive load of $150 \mathrm{MPa}$ and simultaneously currentimpulse treatment (Fig. 5) have shown that it was only possible to reduce the compression limit in the severely creep deformed specimens (see Fig. 5 d). Here, the currentinduced dislocation motion causes an interaction between the interfacial and super dislocations present in the microstructure. The reduction of the dislocation density resulting from this interaction leads to material softening by recovery processes. Such interactions were visible in TEM images of severely creep deformed and current-impulse treated specimens (see Fig. $6 \mathrm{a}$ and b). The current-impulse treatment for the other 
Table 3. Determined K-values for selected elements contained in CMSX-4.

\begin{tabular}{lccccccc}
\hline & \multicolumn{3}{c}{ Elements of the $\boldsymbol{\gamma}^{\prime}$-phase } & \multicolumn{3}{c}{ Elements of the $\gamma$-phase } \\
& $\mathrm{Ni}$ & $\mathrm{Al}$ & $\mathrm{Ta}$ & $\mathrm{Ti}$ & $\mathrm{W}$ & $\mathrm{Co}$ & $\mathrm{Cr}$ \\
\hline $\boldsymbol{\kappa}_{\text {as-cast }}$ & 1.01 & 1.03 & 1.02 & 0.97 & 0.89 & 0.99 & 0.92 \\
$\boldsymbol{\kappa}_{\text {heat-treated }}$ & 0.99 & 0.98 & 0.96 & 0.96 & 1.06 & 1.06 & 1.15 \\
$\boldsymbol{\kappa}_{\varepsilon=0.01 \%}$ & 1.03 & 1.06 & 1.27 & 1.23 & 0.84 & 0.86 & 0.81 \\
$\boldsymbol{\kappa}_{\varepsilon=0.5 \%}$ & 1.02 & 0.99 & 1.21 & 1.15 & 0.89 & 0.88 & 0.84 \\
\hline
\end{tabular}
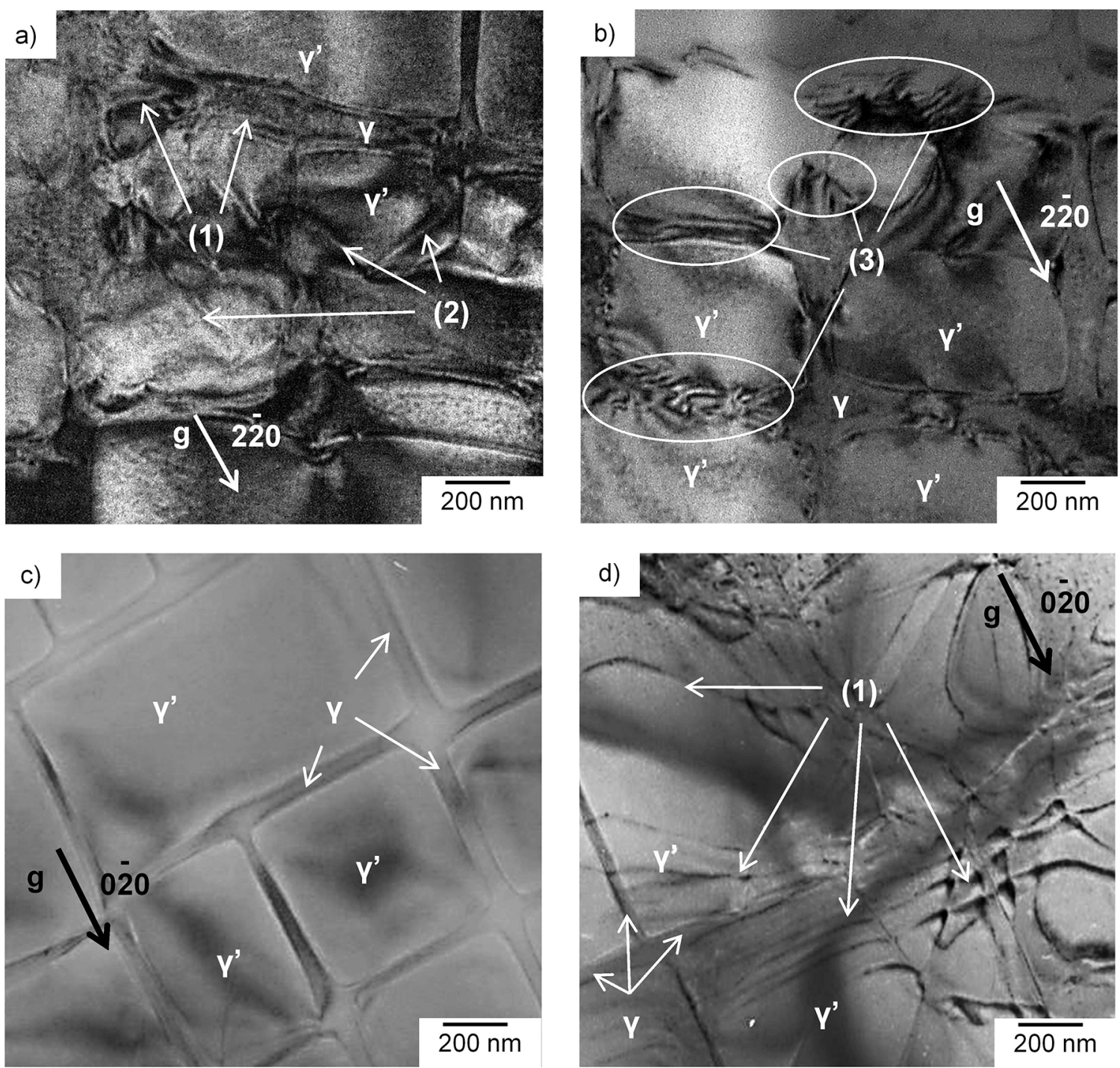

Figure 6. TEM images of lamella prepared by focused-ion beam cutting from creep deformed CMSX-4 $(\varepsilon=0.5 \%)$ : a) prior to and b) after current-impulse treatment, and TEM images of a heat treated specimen of CMSX-4: c) prior to and d) after current-impulse treatment (test parameters according to Table 3); with (1) interfacial dislocations, (2) super dislocations and (3) interaction between (1) and (2).

types of specimens led to an increase in the compression limit and thereby to material hardening. A significant increase in the compression limit can be detected particularly following the current-impulse for the heat-treated material (cf. Fig. 5 b). The corresponding TEM images of these specimens (Fig. $6 \mathrm{c}$ and d) depict an increased number of interfacial dislocations due to the current-impulse treatment.
The heating of the dislocation core during the electric current pulse treatment on metallic materials was also investigated in ${ }^{23}$. The investigations show that the resulting increase in dislocation activity, which leads to annihilation of the dislocations, can not be explained only by the local heating of the dislocation core. 
It was possible to observe a material hardening in the heat treated state with continuous impulse tests. This would be rather disadvantageous for subsequent forming processes. In contrast to this, significant material softening occurred in the severely creep deformed state. For this reason, it would be interesting in subsequent investigations to subject these two states to a creep deformation following current-impulse treatment. For a possible material hardening of heat treated specimens, the service life of, for example turbine blades, might be elevated with regard to creep loading.

\subsection{Change in elemental distribution upon impulse treatment}

The effect of electromigration is described in the literature primarily for pure metals such as $\mathrm{Al}^{16,17}$ or $\mathrm{Cu}^{18}$. The small, impulse-related change in the local chemical composition of $\mathrm{Al}$ in all four investigated material conditions (Table 3 ) shows that only very low electromigration of $\mathrm{Al}$, as element with high diffusion coefficient in nickel-based alloys ${ }^{19}$, occurs in the nickel-based superalloy CMSX-4 for the chosen current densities. This corresponds to the observations of Black, who gives minimum current densities of $5 \mathrm{kA} / \mathrm{mm}^{2}$ in order to be able to observe a significant effect of electromigration of aluminium ${ }^{16,17}$.

The pulse-related specimen heating to temperatures up to $550^{\circ} \mathrm{C}$ is not sufficient to initiate substantial diffusion processes in this alloy. Thus, the observed redistribution of the alloying elements can be attributed to the influence of the high-density electrical current. Specifically, it was possible to measure a significant change in the $\gamma$ - and $\gamma$ '-forming elements in the creep deformed specimens. This behaviour, similar to that for compensating the concentration by developing a raft, suggests the interaction between $\mathrm{Cr}$, $\mathrm{Co}$ and the interfacial dislocations in the creep deformed microstructure ${ }^{20}$. Due to this interaction, current-impulse treatments might be used to recover the initial state in creeped material.

\section{Conclusions}

The influence of high density electrical current impulses on the stress-strain response and the microstructure evolution in single crystal nickel-based superalloy CMSX-4 was investigated. The effects were analzyed for the as-cast, heat treated and creep deformed $(\varepsilon=0.01 \%$ and $\varepsilon=0.5$ $\%$ ) conditions of the material and main results can be summarized as follows:

- The occurrence of both hardening in severely creep deformed specimens as well as softening in all the other states was observed upon superposition of high density current impulses. The magnitude of the effect at current density of $2.3 \mathrm{kA} / \mathrm{mm}^{2}$ was low as compared to the compression limit of the material. Higher current densities might further increase the effect in the high temperature alloy CMSX-4.
- A significant current-impulse related redistribution of the $\gamma$ - and $\gamma$ '-forming elements could only be observed in creep deformed specimens. The current-induced dislocation motion suggests an interaction between the elements $\mathrm{Cr}$, $\mathrm{Co}$ and the interfacial dislocations.

- $\quad$ Since electric current impulses are affecting the deformation behaviour of the casting alloy CMSX4 featuring a low formability, even higher effects can be assumed in nickel-based wrought alloys.

\section{Acknowledgement}

Funded by the Deutsche Forschungsgemeinschaft (DFG, German Research Foundation) - Project number 264020728.

\section{References}

1. Okazaki K, Kagawa M, Conrad H. A study of the electroplastic effect in metals. Scripta Metallurgica. 1978;12(11):1063-1068.

2. Okazaki K, Kagawa M, Conrad H. Effects of strain rate, temperature and interstitial content on the electroplastic effect in titanium. Scripta Metallurgica. 1979;13(6):473-477.

3. Okazaki K, Kagawa M, Conrad H. Additional results on the electroplastic effect in metals. Scripta Metallurgica. 1979;13(4):277-280.

4. Okazaki K, Kagawa M, Conrad H. An evaluation of the contribution of skin, pinch and heating effects to the electroplastic effect in titanium. Materials Science and Engineering. 1980;45(2):109116.

5. Cao W, Sprecher AF, Conrad H. Measurement of the electroplastic effect in Nb. Journal of Physics E: Scientific Instruments. 1989;22(12):1026-1034.

6. Sprecher AF, Mannan SL, Conrad H. On the temperature rise associated with the electroplastic effect in titanium. Scripta Metallurgica. 1983;17(6):769-772.

7. Sprecher AF, Mannan SL, Conrad H. Overview no. 49: On the mechanisms for the electroplastic effect in metals. Acta Metallurgica. 1986;34(7):1145-1162.

8. Varma SK, Cornwell LR. The electroplastic effect in aluminum. Scripta Metallurgica. 1979;13(8):733-738.

9. Goldman PD, Motowidlo LR, Galligan GM. The absence of an electroplastic effect in lead at 4.2 K. Scripta Metallurgica. 1981;15(4):353-356.

10. Fiks VB. Interaction of Conduction Electrons with Single Dislocations in Metals. Journal of Experimental and Theoretical Physics. 1981;53(6):1209-1211.

11. Link T, Epishin A, Paulisch M, May T. Topography of semicoherent $\gamma / \gamma^{\prime}$-interfaces in superalloys: investigation of the formation mechanism. Materials Science and Engineering: $A$. 2011;528(19-20):6225-6234.

12. Gerstein G, Nowak M, Bierbaum MS, Zhuravina T, Schaper M, Bach FW. Increase the Deformability of NiCo Single Crystals Using of Electrical Pulse-Like Currents. Key Engineering Materials. 2012;504-506:143-148. 
13. Demler E, Gerstein G, Dalinger A, Epishin A, Rodman D, Nürnberger F. Influence of High-Current-Density Impulses on the Compression Behavior: Experiments with Iron and a NickelBased Alloy. Journal of Materials Engineering and Performance. 2017;26(1):177-184.

14. Tsuno N, Shimabayashi S, Kakehi K, Rae CMF, Reed RC. Tension/Compression Asymmetry in Yield and Creep Strenghts of Ni-Based Alloys. In: Superalloys 2008 - Proceedings of the 11th International Symposium on Superalloys. 2008 Sep 1418; Champion, PA, USA. The Minerals, Metals and Materials Society; 2008. p. 433-442.

15. Petrow G. Metallographic Etching. Techniques for Metallography, Ceramography, Plastography. 2nd ed. Materials Park: ASM International; 1999.

16. Black JR. Electromigration failure modes in aluminum metallization for semiconductor devices. Proceedings of the IEEE. 1969;57(9):1587-1594.

17. Black JR. Elektromigration-A brief survey and some recent results. IEEE Transactions on Electron Devices. 1969;16(4):338-346.

18. Ryu C, Kwon KW, Loke ALS, Lee H, Nogami T, Dubin VM, et al. Microstructure and reliability of copper interconnects. IEEE Transactions on Electron Devices. 1999;46(6):1113-1120.
19. Karunaratne MSA, Cox DC, Carter P, Reed RC. Modelling of the Microsegregation in CMSX-4 Superalloy and its Homogenisation During Heat Treatment. In: Pollock TM, Kissinger RD, Bowman RR Green KA, McLean M, Olson S, et al., eds. Superalloys 2000. Proceedings of the 9th International Symposium on Superalloys; 2000 Sep 17-21; Champion, PA, USA. The Minerals, Metals and Materials Society; 2000. p. 263-272.

20. Buffiere JY, Ignat M. A dislocation based criterion for the raft formation in nickel-based superalloys single-crystals. Acta Metallurgica et Materialia. 1995;43(5):1791-1797.

21. Dubiel BT, Szyrska-Filemonowicz A. Microstructural changes during creep of CMSX-4 single crystal Ni base superalloy at $750^{\circ}$ C. Journal of Microscopy. 2010;237(3):364-369.

22. Demler E, Gerstein G, Dalinger A, Nürnberger F, Epishin A, Molodov DA. Effect of Electrical Pulses on the Mechanical Behavior of Single Crystals of Nickel-Based CMSX-4 Superalloy and the Mobility of Low-Angle Grain Boundary in Aluminum Bicrystals. Bulletin of the Russian Academy of Sciences: Physics. 2018;82(9):1079-1085.

23. Salandro WA, Jones JJ, Bunget C, Mears L, Roth JT. Electrically Assisted Forming - Modeling and Control. Cham: Springer International Publishing; 2015. 